\title{
7. Social media and \\ disaster communication A case study of Cyclone Winston
}

\begin{abstract}
This article presents an analysis of how social media was used during Tropical Cyclone Winston, the strongest recorded tropical storm that left a wake of destruction and devastation in Fiji during February 2016. Social media is increasingly being used in crises and disasters as an alternative form of communication. Social media use in crisis communication varies according to the context, the disaster and the maturity of social media use. Fiji's experience during TC Winston contributes to the growing literature as it shows how social media was used during each stage of a disaster in a developing country. The article finds that before the cyclone, people used social media to share information about the cyclone and to be informed about the cyclone. During the cyclone, individuals used social media to share their experiences with some citizens capturing the cyclone as it happened and even one citizen live-tweeted her ordeal during the cyclone. Finally, following the cyclone, the hashtag \#StrongerThanWinston was coined as a rallying point to bolster a sense of national solidarity.
\end{abstract}

Keywords: crisis response, Cyclone Winston, cyclones, Fiji, disaster communication, Pacific Islands, social media

\section{GLEN FINAU, JOPE TARAI, RENATA VAREA, JASON TITIFANUE and ROMITESH KANT \\ University of the South Pacific, Suva \\ JOHN COX \\ La Trobe University, Melbourne}

\section{Introduction}

This article presents an analysis of social media use in disaster communication during one of the most destructive tropical cyclones to ever be recorded in the world. On 20 February 2016, Tropical Cyclone Winston made landfall in Fiji- a category five cyclone that was the strongest cyclone to be recorded in the Pacific (Robie \& Chand, 2017). The cyclone affected both Tonga and Fiji, but it was Fiji that bore the brunt of the cyclone. Hitting Fiji in the early hours of morning, the cyclone left a wake of devastation causing US\$460 million in damages to private property, infrastructure and disrupting water, power and sanitation 
supplies (Radio NZ, 2016). The cyclone also caused the deaths of 44 people and left thousands of Fijians homeless (NDMO, 2016).

The article examines how social media was used before, during and after the cyclone. The affordances of social media that allow people to create content and make certain topics popular facilitated faster dissemination of information and allowed multiple perspectives to be shared and distributed on social media (Keim \& Noji, 2011). Furthermore, the dynamic, interactive and visually appealing nature of social media content has led to innovative uses of social media at each stage of TC Winston. Before the cyclone, respondents from rural areas revealed that they were more informed about the impending cyclone because of social media rather than through traditional media. During the cyclone, some Fijians used social media to live-tweet their experiences and share pictures and videos of the cyclone as it happened. The main social media platforms used were Facebook and Twitter. This was picked up by media organisations that broadcast this to the world. Following the cyclone social media was used by various groups in quite innovative ways. Affected Fijians used social media to show the impact of the cyclone and the damage caused. Social media was also used to organise fundraising events and crowd source for funding to assist those affected. Development organisations and country agencies used social media to highlight their relief efforts, and finally, the hashtag \#StrongerThanWinston was coined to bolster a sense of national solidarity in the wake of the disaster.

\section{Social media and natural disasters}

Social media is a broad term that encompasses technologies that facilitate the creation, dissemination and sharing of content via online communities and virtual networks (Obar \& Wildman, 2015). Social media is often described as Web 2.0 as it is an evolution from the traditional online websites where content was owned and controlled by the website owners (Kaplan \& Haenlein, 2010). Furthermore, social media focuses on building networks and communities online (Leonardi et al., 2013). These networks are based on traditional offline relationships but are created via online connections (Ellison, 2007). The social network sites of individual users are thus personalised based on the individual's personal interests but also based on the user's connections, relationships and networks (Xiang \& Gretzel, 2010).

A relatively young technology, social media has now become a ubiquitous and pervasive part of modern day communication (Kaplan \& Haenlein, 2010). Social media is also playing an important role as a tool for disaster communication (Houston et al., 2015). Scholars have researched how social media was used in various natural disasters. Sutton, et al., (2008) found that social media usage may be conceptualised in two categories: (1) (Personal Communication) passive dissemination of information; and (2) systematic usage as an emergency 
management tool. Sutton et al. (2008) argue that because of the speculative nature and the infancy of these applications, dissemination of information is the primary way that social media is used in disaster communication. However, later research has found that the maturity of these technologies and users growing use of social media has led to increasing innovative and active uses of social media during natural disasters by the public and the government (Lachlan et al., 2016). Bird et al. (2012) conducting a survey of social media use during the 2010/2011 Queensland and Victorian Floods in Australia, found that Facebook was used to provide real-time information on the flood that helped local authorities provide relief effort and mobilise their resources to assist communities affected by the flood.

Social media for disaster communication is thus continually evolving and its application is also shaped by the context, users and the nature of the crisis. While research has examined the use of social media at the different stages of a natural disaster, most studies have been conducted in developed economies, where ICT infrastructure is more developed, and citizen and government use of social media for disaster communication is more sophisticated (Acar \& Muraki, 2011). This article contributes to the growing body of literature by examining the innovative ways in which social media was used in a developing Pacific island country during the strongest recorded tropical cyclone ever recorded in the Southern Hemisphere to date: Tropical Cyclone Winston (TC Winston).

\section{Methods}

Data for the study was drawn from multiple sources and is primarily qualitative in nature. Data was collected from semi-structured interviews conducted with individuals residing in rural areas of Fiji, social media data from Facebook and Twitter, and the authors also used their own experiences of being active social media users during the cyclone.

The semi-structured interviews were conducted with rural villagers in the province of $\mathrm{Ba}$. The province of $\mathrm{Ba}$ is located on the western side of the main island Viti Levu and was one of the worst affected provinces from TC Winston (Esler, 2016; Sattler, 2016). Interviews were conducted with 15 rural villagers and sought to identify how social media was used as a disaster communication tool. Table 1 below provides demographic details of our interlocutors in Ba. We have de-identified them and given them pseudonyms for referencing their quotes in our discussion.

An analysis of social media pages - Facebook and Twitter-were also examined to explore social media usage during TC Winston. The two most trending hashtags related to TC Winston were \#StrongerThanWinston and \#TCWinston. These hashtags were used as the search terms on the social media pages and the search results. We also used other search terms such as Cyclone Winston and Tropical Cyclone Winston on Facebook's search function. The search results 


\begin{tabular}{|c|c|c|c|c|}
\hline \multicolumn{4}{|c|}{ Table 1: Demographic details for interlocutors in Ba } \\
\hline No. & Pseudonym & Gender & Age & Occupation \\
\hline 1 & Make & F & 19 & Domestic Duty \\
\hline 2 & Naca & F & 17 & Student \\
\hline 3 & Lesi & F & 40 & Domestic Duty \\
\hline 4 & Sia & F & 30 & Domestic Duty \\
\hline 5 & Sala & F & 24 & Domestic Duty \\
\hline 6 & Laini & F & 17 & Student \\
\hline 7 & Ini & F & 26 & Nurse \\
\hline 8 & Dan & M & 28 & Unemployed \\
\hline 9 & Mary & F & 25 & Domestic Duty \\
\hline 10 & Tu & F & 27 & Domestic Duty \\
\hline 11 & Tia & M & 23 & Farmer \\
\hline 12 & Suli & M & 30 & Farmer \\
\hline 13 & Mori & M & 31 & Soldier \\
\hline 14 & Lui & M & 38 & Farmer \\
\hline 15 & Luke & M & 54 & Security Officer \\
\hline
\end{tabular}

were then analysed to explore the way social media was being used by various parties during the disaster.

Lastly, except for one author, the other authors were all in Fiji during the cyclone. The authors witnessed first-hand the devastation of the cyclone and were also part of the unprecedented use of social media during the cyclone both as consumers and creators of content during TC Winston. These experiences inform the primary data collected from the interviews and the data extracted from Facebook and Twitter.

\section{Disaster preparedness and social media: Ba district before TC Winston}

On the 20 February 2016 word of an impending cyclone had yet to reach the people of Votua in the province of $\mathrm{Ba}$. Unbeknown to them was the fact that the largest cyclone to ever hit the Southern Hemisphere was heading in their direction (Sattler, 2017). As the day went on, the villagers completed their daily routines of fishing and cleaning. Amidst the normal hustle and bustle, the few people who had access to mobile internet took time to sign into their Facebook accounts to update themselves on familial events and news in general. Laini, a young lady from Votua describes how she had logged onto Facebook to 'update her status'. Upon logging in, she scrolled down her news-feed to update herself on the lives of her Facebook connections, she received a very different update 
from the typical Facebook social networking. She saw post after post from friends and family who were better connected to news updates, relating to an imminent cyclone scheduled to make landfall that very afternoon. The posts ranged from people warning their friends and family, to simply being posts about how families were preparing to 'greet' the cyclone. She recalls calling out to a neighbour to ask if anyone had heard about the cyclone, to which the neighbour replied saying that his son had just called from Suva to check if they had prepared. For much of the community, word of this impending disaster, was too long in reaching them. Pita (pseudonym), one of the youths from Votua, also recalls being online when a family member he was chatting with had told him to make sure that the family was prepared and to expect flooding during the cyclone. In such instances as shown by Luisa and Pitas stories, the typically mundane digital chatter of social media provided a means to warn citizens of the impending cyclone.

Social media is an often-disregarded tool of 'those young people' (Haddon, 2015). The dialogue on social media is often seen to simply be 'social'. Over time, these mundane chatter tools have evolved to become powerful means of disseminating information. Social media platforms have come to play a role in politics, education, and now, disaster awareness. Research by Yila et al. (2013), highlights that as far back as 2009, social media was being employed in Fiji to disseminate information on floods taking place in the Ba province of Fiji. Given that in 2009 social media was still a very new technology to Fiji and the Pacific, the speed at which individuals harnessed this tool for keeping informed

\section{Figure 1: Internet users in 10 Pacific countries, 2000-2016}

\section{Internet Users Per 100 People}

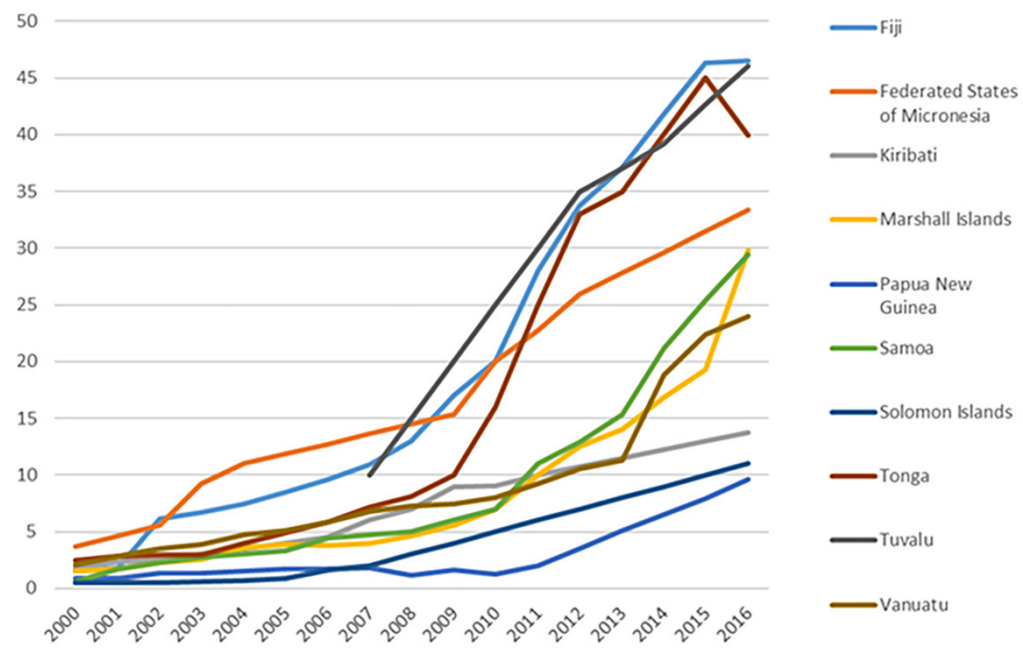

Note:. Internet users per 100 people in 10 Pacific Island Countries. Source: World Bank 
is noteworthy. Figure 1 shows the exponential growth of internet connectivity based on World Bank data from 2000 to 2016.

While there is a large body of research focusing upon the use of social networking sites during and after natural disasters (Veil et al., 2011), there is a paucity of research that encompasses the use of social networking sites prior to natural disasters.

There were even links on social media that allowed users to track the course of the cyclone as it was approaching. Interlocutors preferred using social media instead of traditional media because of the dynamic, rich and interactive content on social media as compared to traditional media. For instance, while mobile network operators sent national text messages to all mobile phone users in Fiji, most respondents were already aware of the cyclone through social media or ignored the text messages as mobile network operators inundated users' message boxes with daily promotional text messages.

\section{Social media live updates during the cyclone}

With the emergence of social networking sites and advancements in digital technologies, social media is becoming an effective tool for disseminating information during disasters (Bird et al., 2012). There is growing academic literature on the importance of the role social media and digital technologies play during natural disasters. In the Pacific, Watson (2012) documented how the introduction of mobile phone services in rural PNG villages, combined with increasing internet accessibility in urban centres and the improvement of websites with suitable, timely information regarding natural disasters, has transformed the accessibility of information, knowledge and communication for many people in PNG.

Bird et al. (2012) conducting a survey of social media use during the 2010/2011 Queensland and Victorian Floods in Australia, found that Facebook was used to provide real-time information on the flood that helped local authorities provide relief efforts and mobilise their resources to assist communities affected by the flood. Bird et al. (2012) demonstrate the important role played by Facebook forums in providing valuable information during and after disasters. In Fiji, Yila, et al. (2013, p. 95) reveal the uptake in the usage of social media for dissemination of information of the floods in Ba from 2009 to 2012. They reveal that some individuals were using social media to extend information, awareness and support. According to them, the increasing usages of digital technologies including social media were facilitating 'new forms of response, creating new forms of social capital' (Yila et al., 2013, p. 95).

Early warnings were distributed through national and social media, and close collaboration between Fiji Meteorological Services (FMS), the private weather forecaster NaDraki, and the National Disaster Management Office. The 
Fiji Meteorological Office, a statutory government agency, used various means including through the Fiji Meteorological Service Facebook page, to provide official weather reports prior to TC Winston. A private weather and climate organisation also provided independent weather updates via the NaDraki Weather Facebook page. These two organisations were the most popular Facebook pages that provided regular updates on TC Winston. The Fiji Meteorological Service Facebook page has an audience of over 32,000 followers while NaDraki Weather is more popular with an audience of over 88,000 followers. ${ }^{1}$ The Fiji government Facebook page ${ }^{2}$ also provided general weather updates in the lead up to and during TC Winston. Apart from providing weather updates, the Fiji Government page also provided details of evacuation centres in affected areas.

On the eve of TC Winston, one person questioned why the government website was failing to provide updated information when compared to the Facebook page, one of the administrators of the Fiji Government page commented that 'we have a link from our [government] site to this Facebook account. Because our updates have to be constant we update through Facebook, which we have set up to allow even those without Facebook to access our page. This way, our updates are more constant and engaging - thanks' (Fiji Government Facebook Page, 2016).

During recent natural disasters, social media has played an increasingly popular role in the crisis communication ecology (Bruns et al., 2012; Palen \& Liu, 2007). Research has shown how affected members of the public use these platforms to share up-to-date information and images on their statuses with friends and family (Takahashi et al., 2015). Social media, in particular, have become important channels for communication, playing complementary roles to those played by traditional media (Veil et al., 2011). This is particularly salient considering that in 2013, the social media platform Twitter unveiled a new service called Twitter Alerts, designed to prioritise information from credible organisations during crises when other communications channels are not accessible. Similarly, in October 2014, Facebook introduced Safety Check, a service that allows users to communicate that they are safe and check the status of their acquaintances during a crisis (Facebook, 2014).

Fijians from different parts of Fiji shared their first-hand experience of TC Winston on social media, primarily Facebook. In carrying out this role, people recognised that social media platforms provided a means by which they could broadcast information without the need of a media agency, in the form of personal commentary, photos or stories and to share these with the world. The function of citizen journalism coincided with the notion of communicating information about their own personal wellbeing through social media or using information available in social media to monitor the wellbeing of others.

There was a particularly interesting case where a young female living on the 
Western side of Viti Levu, named Cayla Tikaram, live tweeted her experience during the TC Winston while huddled with her family in a cupboard. The story was picked up by The New Zealand Herald, Daily Mail (UK), and even CNN (NZ Herald, 2016). There were also residents in Taveuni and Savusavu that recorded and uploaded videos of the cyclone onto Facebook ${ }^{3}$. Ironically, these individuals were able to do this because the areas where they live is not connected to the national electrical powerlines and therefore uses diesel generators. While there was a nationwide electrical blackout in Fiji, these individuals were able to live tweet, record and upload the effects of the cyclone as it happened on social media. The international media and international community were able to see the impact of the cyclone as it happened, and this contributed to the immediate response in relief efforts.

\section{\#StrongerThanWinston: Rallying response}

Following a natural disaster, social media have been shown to be used by individuals to indicate their status, request for assistance, share their ordeal and post pictures and videos of the aftermath (Acar \& Muraki, 2011; Qu et al. 2011). Social media are also used by those who were not physically present at the location of the natural disaster to show their sympathy from a distance towards those affected. In post-recovery situations, social media have also been shown to facilitate communication between the public and the government (Annamalai, Koay, \& Lee, 2014).

The \#StrongerThanWinston hashtag was the 'brain child' of a Fijian disaster risk management official. Hughes and Palen (2012) argue that social media have changed the role of Public Information Officers (PIOs) of National Incident Management Systems. Conducting interviews with $25 \mathrm{PIOs}$, the study finds that social media have expanded the scope and nature of work activity and communication that exist between PIOs, media and members of the public. The official had been part of the Fijian Government delegation that visited and assisted with the relief efforts after Cyclone Pam in Vanuatu. This experience informed the official's observations about the necessity of communications in fostering unity in coordination efforts for disaster risk management.

Vanuatu had the \#WithVanuatu hashtag which garnered online support mostly on Twitter. However, the official believed that the \#WithVanuatu hashtag created division rather than unity within Vanuatu. As the official put it, 'it seemed to make the people a separate entity altogether'. The call for \#WithVanuatu seemed more of an appeal to those outside Vanuatu, which in a way deflected from those within Vanuatu who faced the disaster. The official claimed that this narrative was perhaps more targeted for humanitarian groups and external actors. This experience shaped and informed the creation of the \#StrongerThanWinston hashtag to an extent. 
For several days after the devastation of Cyclone Winston, there were no comprehensive aerial images of the damages. This was until the Royal New Zealand Air Force captured full scale images of the decimated island of Koro. The official shared how their noisy briefing room suddenly fell silent as the images of flattened homes and ruined vegetation were projected on their briefing screen. Their team was briefed that a category 5 cyclone has the 'strongest' intensity and that the images they had seen matched the expected devastation of such a category. The strongest category matched a stronger people, despite its devastation and havoc. This laid the conceptual foundation of \#StrongerThanWinston in seeking to embolden and empower not only Fijians who were directly affected but also those who were in a better position to lend a helping hand. The official noted how social media galvanised public opinion and emotional sentiment in Fiji much faster than any other medium in times of disaster.

The expanse of internet access, affordability and live updating capabilities of digital technologies, provided the impetus for the \#StrongerThanWinston narrative, which spread like wild fire on Fiji's digital landscape. This began with an unassuming Facebook post, which caught onto Twitter and ultimately began trending within Fiji's social networking sites. Fiji's largest Facebook GroupChat (Fiji) (www.facebook.com/groups/LETSTALK11/) ${ }^{4}$, has over 200,000 active accounts, the \#StrongerThanWinston hashtag had over 70 posts in the nine months after Cyclone Winston. The highest post garnered well over 1500 reactions and more than 140 comments. On Fiji's 'Twittersphere' the hashtag gained well over 2400 mentions and has been retweeted well beyond that figure. The official confirmed that the narrative had gone viral first, and then it was used in official government agency statements. It was as if the message was vetted by the public first then regurgitated by the state, which only heightened its intensity and popularity.

By that point the \#StrongerThanWinston narrative captured a three-tier focus. First, it emphasised the people being stronger than the disaster, which situated Fijians not so much as victims but as overcomers of the devastation. Second, it galvanised the idea that part of being stronger as a people was in helping one another as Fijians. This fed directly into the government's efforts at mobilising public unity and cooperation towards its relief efforts. Third, the narrative became an easy and convenient frame for intergovernmental organisations, disaster relief agencies and other external actors.

The digital public responses towards \#StrongerThanWinston varied, predicated on social networking platforms and focus. Out of these responses there is a notable set of trends observed. The first and most prominent were individual personal accounts and documentation of destruction. These included a wide variety of images and videos of people's homes, property and some of their livestock being caught in the devastation. This was followed by the empowered trend, where statuses 
and tweets began to project the narrative of being \#StrongerThanWinston. It was also fascinating to note the distinction in class and location in the variety of digital discussions. This was evidenced when some digital Fijian citizens in the urban and more privileged areas were reproached by others for relentlessly lamenting the power disruptions, while many others were without homes and some had lost their loved ones, as a post on one of Fiji's earliest Facebook forums indicated.

Another trend in the \#StrongerThanWinston digital discourse, touched on Fiji's foreign policy. As the relief efforts, pledges and promises began trickling in, many began to not only laud the Australian and New Zealand response but also question other international partners that seemed delayed in their offer of support. The Australian and New Zealand assistance was extensive and immediate in the wake of the disaster. Australia had committed a total of AUD \$35 million with a wide range of technical support that assisted the government's relief efforts (Australian Government, 2017). New Zealand provided the muchneeded aerial support and medical services that were crucial, especially for the outer islands (New Zealand Government, 2016). Both governments were visible with their defence forces on the ground and in the water, for the outer islands.

The immediate presence and efforts of these two countries was well received and it began a trend of digital discussions that questioned Fiji's foreign policy assertions. After Fiji's suspension from the Pacific Island Forum in 2009, the Australian and New Zealand Government was never seen in the same light as it once was by the Bainimarama administration (Green, 2013). With the Look North Policy and the looming presence of China, Fiji began seeking alternative partners away from Australia and New Zealand (Tarte, 2011; Wesley-Smith \& Porter, 2010). Fiji was welcomed back into the Pacific Island forum after its 2014 elections, but Prime Minister Bainimarama was blunt in calling for the removal of Australia and New Zealand as members. The public impression of these sentiments erupted in the digital discussions as many questioned the absence, if not glacial response, of alternative partners compared to their Australian and New Zealand counterparts. As a social media user posted, 'Where is China and Russia in our hour of need?', referencing a news link of Bainimarama's statement against Australia and New Zealand. Another user asserted, 'NZ and Australia's humanitarian efforts are above politics in such times'. In this regard, Australia's and New Zealand's success in public diplomacy was evidenced by this trend in digital discussions.

These sentiments are a snapshot of the wider digital discussions that permeated Fiji's digital landscape. The birth of the \#StrongerThanWinston hashtag and narrative proved successful in rallying a sense of empowerment and public support. This was evident in the online observations and data gathering that was done in the months following Cyclone Winston. In addition to this \#StrongerThanWinston was mentioned, posted, tweeted and shared well over 2000 times across Fjii's social networking sites. However, alongside this narrative emerged nuanced trends 
in public responses, expressed by users as digital citizens. These trends mark an interesting interplay of public engagement, perception and communication in disaster relief efforts. On one hand online users expressed their horror and pain at the devastation, while at the same most viewed it as an act of God, as opposed to the connections to climate change. These sentiments sought to promote the idea of 'sin', 'shame' and belief. While this was clear, the public appeared to directly engage and rally around being 'stronger' than the given adversity caused by the devastation, through social media. These aspects tended to conflict on certain terms considering the predominantly secular approach of state and non-state agencies. Despite the contending trends that ran alongside the \#StrongerThanWinston hashtag, the underlying empowering and unifying narrative was a major success. This was evidenced by widely known public support that was overwhelming, to the point that individual families visited villages on their own and made direct personal forms of assistance.

The \#StrongerThanWinston was also used prominently by international NGOs and foreign governments. NGOs and foreign governments co-opted the hashtag to show their relief efforts following the cyclone. Even NGOs who did not intend to take on journalistic roles became, as Spyksma (2017) describe 'unintentional journalists'. Using the case study of the NGO 350.org and Cyclone Pam in Vanuatu, Spyksma argues that members of 350 .org, by producing reports about the passing of Cyclone Pam in Vanuatu, 2015, filled a void in global news reporting from the Pacific region. The eyewitness reporting was intended to highlight the impacts of climate change through the severity of Cyclone Pam. While the intention was advocacy for climate change action, Spyksma (2017) argues that the NGO became unintentional journalists as they filled a gap in international reporting by putting Pacific voices at the centre, in contrast to traditional reporting of international media organisations.

Spyksma further argues that the act of reporting on Cyclone Pam 'created a discursive space that disrupted the status quo of climate change reporting in and about the region: by using global structures to amplify local voices' (p. 16). Spyksma (2017) also describes how 350.org used Facebook to report about Cyclone Pam. 350.org created a live blog on their Facebook page to respond to audiences wanting to be constantly informed about the relief and recovery efforts. YouTube was also used where videos before and after the storm were uploaded. Interestingly, Twitter was not described at all as being used by 350 .org and while this is surprising in Western countries, it is not in the Pacific, where Facebook and YouTube are the most popular social media platforms (Author, 2016).

As noted by Alexander (2014), social media can create a sense of social cohesion that promotes therapeutic initiatives, fosters a sense of online and office identity and enhances voluntarism. Following TC Winston, there was an outpouring of donations and support from Fijians living abroad and the international 
community. Countless fundraising events were organised using social media to help raise funds and collect items that would be useful to affected Fijians. This is consistent with other studies that have found social media fundraising campaigns have elicited considerable responses from public donors (Gao et al., 2011; Lobb et al., 2012). The hashtag became the rallying point for individuals around the world as Fiji tried to rebuild and restore normalcy following the Cyclone.

\section{Conclusion}

This article has provided an analysis of how social media was used before, during and after Tropical Cyclone Winston. The article contributes to the growing literature on social media and disaster communication by providing a case study of TC Winston. It shows innovative and serendipitous uses of social media during the cyclone from informing citizens about the cyclone, allowing individuals to broadcast their experiences during the cyclone and as a rallying point that brought the nation and the international communities together to assist Fijians recover from the cyclone.

Social media did not replace the traditional modes of communication but rather was complementary to these conventional forms of communication. Social media also complemented mainstream media by allowing Pacific voices to tell their stories and share their experience with the cyclone. This form of reporting has been highlighted as necessary in the Pacific to counter what Robie (2014) describes as 'carbon colonialism', referring to Western media outlets' coverage of the impact of climate change in the Pacific. Robie (2014) argues that global inaction to climate change can be attributed to the manipulation of the media due to the "vested interests such as the coal industry and political-economical ideologues pushing neoliberal growth policies' (p. 32). In a similar vein, Spyksma (2017) argues that personal stories from Pacific Islanders are needed to counter the dominant media discourses that obfuscate developed countries' role in global warming. Social media has created a space for Pacific Islanders' voices to be heard and the severity of Cyclone Winston being a consequence of anthropogenic climate change.

While revolutionary in disaster communication, social media also has limitations, especially in developing countries, where internet coverage is limited and costs of accessing social media are prohibitive (Finau et al. 2016). Furthermore, some authors have argued that social media may lead to the spread of false information and rumours that could lead to public anarchy (Bird et al. 2012). However, the data from the study reveal that information shared on social media was quite accurate and that people relied on information shared by their relatives, friends and trusted pages. While there were rumours circulating on social media, these fake stories emerged following the cyclones and related to conspiracy theories about the cause of the cyclone (Cox et al., 2018). 


\section{Notes}

1. As at 21 April 2018, Fiji Meteorological Service (@FijiMetService) had 53,070 followers www.facebook.com/FijiMetService

2. The Fiji government Facebook page (www.facebook.com/FijianGovernment/) has more than 133,000 likes, and the NaDraki weather page (www.facebook.com/ NaDrakiFiji/) has more than 103,000 likes

3. YouTube video of resident in Taveuni video recording the Cyclone: www.youtube. com/watch?v=kRrTUvFlTCM

4. www.facebook.com/groups/LETSTALK11/

\section{References}

Acar, A., \& Muraki, Y. (2011). Twitter for crisis communication: lessons learned from Japan's tsunami disaster. International Journal of Web Based Communities, 7(3), 392-402.

Alexander, D. E. (2014). Social media in disaster risk reduction and crisis management. Science and engineering ethics, 20(3), 717-733.

Annamalai, C., Koay, S. S., \& Lee, S. M. (2014). Role of social networking in disaster management: an empirical analysis. Journal of Computation in Biosciences and Engineering, 1(3), 1-5.

Australian Government. (2017). Tropical Cyclone Winston-Relief and Response. Retrieved from http://dfat.gov.au/aid/topics/investment-priorities/building-resilience/ humanitarian-preparedness-and-response/tc-winston/pages/default.aspx

Bird, D., Ling, M., \& Haynes, K. (2012). Flooding Facebook - the use of social media during the Queensland and Victorian floods. The Australian Journal of Emergency Management, 27(1), 27.

Bruns, A., Burgess, J. E., Crawford, K., \& Shaw, F. (2012).\#qldfloods and@ QPSMedia: Crisis communication on Twitter in the 2011 south east Queensland floods.

Cox, J., Finau, G., Kant, R., Titifanue, J., Tarai, J. (2018). Disaster, divine judgement and original sin: Christian interpretations of Tropical Cyclone Winston and climate change in Fiji. The Contemporary Pacific. 30(2), 380-411.

Facebook (2014). Crisis Response. Retrieved from https://www.facebook.com/about/ crisisresponse/

Ellison, N. B. (2007). Social network sites: Definition, history, and scholarship. Journal of Computer-Mediated Communication, 13(1), 210-230.

Esler, S. (2016). Post-disaster needs assessment-Tropical Cyclone Winston, February 20, 2016. Government of Fiji. Retrieved from www.gfdrr.org/sites/default/files/ publication/Post $\% 20$ Disaster\%20Needs\%20Assessments\%20CYCLONE\%20WINSTON\%20Fiji\%202016\%20(Online\%20Version).pdf

Fiji Government Facebook Page (2016). Reply to post on Cyclone Winston. www. facebook.com/FijianGovernment/

Gao, H., Barbier, G., \& Goolsby, R. (2011). Harnessing the crowdsourcing power of social media for disaster relief. IEEE Intelligent Systems, 26(3), 10-14.

Green, M. (2013). Persona non grata: Breaking the bond: Fiji and New Zealand, 20042007: Dunmore Publishing.

Haddon, L. (2015). Social media and youth. The International Encyclopedia of Digital Communication and Society.

Houston, J. B., Hawthorne, J., Perreault, M. F., Park, E. H., Goldstein Hode, M., Halliwell, M. R., McElderry, J.A. (2015). Social media and disasters: a functional framework for 
social media use in disaster planning, response, and research. Disasters, 39(1), 1-22. Hughes, A. L., \& Palen, L. (2012). The evolving role of the public information officer: An examination of social media in emergency management. Journal of Homeland Security and Emergency Management, 9(1).

Kaplan, A. M., \& Haenlein, M. (2010). Users of the world, unite! The challenges and opportunities of social media. Business Horizons, 53(1), 59-68.

Keim, M. E., \& Noji, E. (2011). Emergent use of social media: a new age of opportunity for disaster resilience. American Journal of Disaster Medicine, 6(1), 47-54.

Lachlan, K. A., Spence, P. R., Lin, X., Najarian, K., \& Del Greco, M. (2016). Social media and crisis management: CERC, search strategies, and Twitter content. Computers in Human Behavior, 54, 647-652.

Leonardi, P. M., Huysman, M., \& Steinfield, C. (2013). Enterprise social media: Definition, history, and prospects for the study of social technologies in organisations. Journal of Computer-Mediated Communication, 19(1), 1-19.

Lobb, A., Mock, N., \& Hutchinson, P. L. (2012). Traditional and social media coverage and charitable giving following the 2010 earthquake in Haiti. Prehospital and disaster medicine, 27(4), 319-324.

NDMO Fiji (2016). Post-Disaster Needs Assessment. Retrieved from www.ndmo. gov.fj/images/AllDisasterReports/Post-Disaster-Needs-Assessments-CYCLONEWINSTON-Fiji-2016-Online-Version.pdf

New Zealand Government. (2016). New Zealand Medical Assistance Team deployment to Fiji. Retrieved from https://reliefweb.int/report/fiji/new-zealand-medical-assistanceteam-deployment-fiji

New Zealand Herald. (2016). Woman live tweets Cyclone Winston destroying her home in Fiji. Retrieved from www.nzherald.co.nz/world/news/article.cfm?c_ $\mathrm{id}=2 \&$ objectid $=11593149$

Obar, J. A., \& Wildman, S. S. (2015). Social media definition and the governance challenge: An introduction to the special issue.

Palen, L., \& Liu, S. B. (2007). Citizen communications in crisis: anticipating a future of ICT-supported public participation. Paper presented at the Proceedings of the SIGCHI conference on Human factors in computing systems.

Qu, Y., Huang, C., Zhang, P., \& Zhang, J. (2011). Harnessing social media in response to major disasters. In CSCW 2011 Workshop: Designing Social and Collaborative Systems for China.

Radio NZ. (2016, February 25). Fiji govt estimates Winston damage US\$460 million. Retrieved from www.radionz.co.nz/international/pacific-news/297447/fiji-govtestimates-winston-damage-us\$460-million

Robie, D. (2014). 'Carbon colonialism': Pacific environmental risk, media credibility and a deliberative perspective. Pacific Journalism Review, 20(2), 59-75.

Robie, D., \& Chand, S. (2017). Bearing Witness 2016: A Fiji climate change journalism case study. Pacific Journalism Review, 23(1), 186.

Sattler, D. N., Whippy, A., Johnson, J., Vucago, N., \& Graham, J. (2016). Cyclone Winston in Fiji: Climate change risk perceptions, posttraumatic stress, coping, and resilience among survivors. In Symposium on Climate Change Adaptation in the Pacific Region, Lautoka, Fiji. Google Scholar.

Sattler, D. N. (2017). Climate change and extreme weather events: The mental health impact. In Climate Change Adaptation in Pacific Countries (pp. 73-85). Springer, Cham.

Spyksma, H. (2017). Unintentional journalists: The role of advocacy group 350 in filling a news gap for reporting from the Pacific region. Journalism Studies, 1-21. 
Sutton, J. N., Palen, L., \& Shklovski, I. (2008). Backchannels on the front lines: Emergency uses of social media in the 2007 Southern California Wildfires: University of Colorado.

Takahashi, B., Tandoc, E. C., \& Carmichael, C. (2015). Communicating on Twitter during a disaster: An analysis of tweets during Typhoon Haiyan in the Philippines. Computers in Human Behavior, 50, 392-398.

Tarte, S. (2011). Australia and the Pacific Islands: a loss of focus or a loss of direction? Paper presented at the East Asia Forum website.

Titifanue, J., Tarai, J., Kant, R., \& Finau, G. (2016) From social networking to activism: The role of social media in the Free West Papua Campaign. Pacific Studies, 39 (3). 255-281

Veil, S. R., Buehner, T., \& Palenchar, M. J. (2011). A work-in-process literature review: Incorporating social media in risk and crisis communication. Journal of Contingencies and Crisis Management, 19(2), 110-122.

Watson, A. (2012). Tsunami alert: The mobile phone difference The Australian Journal of Emergency Management, 27(4), 46-50.

Wesley-Smith, T., \& Porter, E. A. (2010). China in Oceania: Reshaping the Pacific? (Vol. 1): Berghahn Books.

Xiang, Z., \& Gretzel, U. (2010). Role of social media in online travel information search. Tourism Management, 31(2), 179-188.

Yila, O., Weber, E., \& Neef, A. (2013). The role of social capital in post-flood response and recovery among downstream communities of the Ba River, Western Viti Levu, Fiji Islands. In Risks and Conflicts: Local Responses to Natural Disasters (pp. 79107). UK: Emerald Group Publishing Limited.

Glen Finau is a former lecturer in accounting at the University of the South Pacific. $\mathrm{He}$ is currently on study leave to pursue a PhD in Accounting at the University of New South Wales. glen.finau@usp.ac.fj

Jope Tarai is a teaching staff at the School of Government, Development and International Affairs at the University of the South Pacific.

Renata Varea is a USP Graduate Assistant, she is currently pursuing a Master of Arts degree in Geography.

Jason Titifanue is a teaching staff at the School of Government, Development and International Affairs at the University of the South Pacific.

Romitesh Kant is a teaching staff at the School of Government, Development and International Affairs at the University of the South Pacific.

John Cox is a research fellow at La Trobe University in Melbourne. He is an anthropologist and his PhD was an anthropological study of Papua New Guinea's biggest and longest Ponzi scheme. He also has twenty years experience working in the Pacific region in the areas of education, evaluation and program management. 